\title{
Modern Contraceptive Methods Predict Hemoglobin Levels Among Women of Childbearing Age from DHS 2016
}

\author{
Anissa Abebe Teshome ${ }^{1,2}$ \\ Wondu Garoma Berra ${ }^{3}$ \\ Aschalew Fikru Huryi ${ }^{2}$ \\ 'Department of Food Science and \\ Technology, Haramaya University, Dire \\ Dawa, Ethiopia; ${ }^{2}$ Department of \\ Nutrition and Food Hygiene, School of \\ Public Health, Tongji Medical College, \\ Huazhong University of Science and \\ Technology, Wuhan, 430030, Hubei, \\ People's Republic of China; ${ }^{3}$ Nutrition \\ Unit, Wollega University, Nekemte, \\ Ethiopia
}

Objective: This study aimed to study the association of different modern contraceptive methods and anemia on women of childbearing age.

Methods: The study was conducted based on secondary data from Ethiopia demographic and health surveys (EDHS) in 2016. The study included 12,981, women of childbearing age. The dependent variable is anemia which was defined based on the level of hemoglobin concentration, and was classified as non-anemic (above $12 \mathrm{~g} / \mathrm{dL}$ ) or anemic (below $12 \mathrm{~g} / \mathrm{dL}$ ). The association between anemia with modern contraceptive method and BMI was analyzed using a logistic regression model.

Results: A total of 12,891 non-pregnant women were recruited for this study, $26.3 \%$ (95\% CI: 25.9 to 27.1 ) had anemia, and hemoglobin level was $12.9 \pm 1.7$. The current use of modern contraceptives has substantially reduced the odds of anemia by $50 \%$ compared with non-users. Compared to barrier methods, individual modern contraceptive use showed higher odds ratio of, oral contraceptive pills (OCP) 0.6 (95\% CI: 0.45 to 1.12 ), injectables 0.59 (95\% CI: 0.24 to 1.79 ), implant 0.72 (95\% CI: 0.60 to 0.86$)$ and significantly reduces the risk of anemia. In addition to the contraceptive method, BMI found to improve anemia and the underweight women showed significant effect on an anemia (OR 2.20 (95\% CI 1.58-2. 62)) P=0.000.

Conclusion: The use of hormonal contraceptive methods reduces anemia among women of childbearing age. Moreover, there is an association between BMI and anemia.

Keywords: anemia, BMI, women of childbearing age, contraceptive, DHS

\section{Introduction}

The growth rate of the world population was estimated at $1.13 \%$, which accounts for about 80 million people recorded every year. ${ }^{1}$ According to the United nation, in 2025, approximately the world population will increase from 7.4 billion in 2016 to 8.1. Developing countries will contribute to most of this growth, with more than half from Africa. ${ }^{2}$ In every country, the reproductive rate is a determinant factor for the human development index (HDI), affecting life expectancy, education, per capital income, and other indicators. ${ }^{3}$ Furthermore, Globally, and particularly in sub-Saharan African countries, abortion of unwanted pregnancies create a significant problem in the health delivery system and constitute one of the leading cause of maternal mortality. ${ }^{4}$ Sub-Saharan Africa faces the world's most serious population and reproductive health challenges, including the highest maternal mortality rates, population growth, total fertility, and achieved family planning needs. Ethiopia is one of Africa's most populous countries, with only about $23 \%$
Correspondence: Anissa Abebe Teshome Department of Food Science and Technology, Haramaya University, P. O. Box I38, Dire Dawa, Ethiopia Tel +25I- 911867148

Email umufaruk@yahoo.com 
of women of reproductive age using contraception, which is still low enough to affect fertility, following Nigeria and Egypt. ${ }^{5}$ Family planning helps anticipate and prevent approximately 2.7 million infant deaths and the loss of 60 million health lives in a year. ${ }^{6}$ It helps to avoid unintended pregnancy, abortion and to have enough space between childbirth. ${ }^{7,8}$

The modern methods have been the most acceptable and cost-effective approaches for promoting reproductive health and encouraging socio-economic development around the globe. ${ }^{9}$ To reduce fertility and mortality rates, providing access to affordable family planning (FP) methods is a significant step in helping countries move toward a demographic transition. ${ }^{10}$

Currently, modern contraceptive methods by married Ethiopian women have steadily increased over the last 15 years, rising from $6 \%$ in 2000 to $35 \%$ in 2016 . Injectables use has grown the most, from $3 \%$ in 2000 to $23 \%$ in 2016 , followed by implant use, which has increased from less than $1 \%$ in 2000 to $8 \%$ in 2016 region. $^{11}$ Anemia is one of the critical nutrition problems and remains a massive challenge for human health and social and economic development in developing countries. ${ }^{12}$ Moreover, anemia is a significant public health problem among women of reproductive age that has prolonged adverse health outcomes and affects social and economic development if not taken too seriously in developing countries. According to the WHO report in 2011, around 2.7 billion people, approximately $43 \%$ of the global population, were affected by anemia, most of whom were preschool children, pregnant women, and women of reproductive age. ${ }^{13}$ Generally, $38 \%$ of pregnant women and $29 \%$ of women are anemic globally, while $46 \%$ of pregnant women and $39 \%$ of women are typically anemic in the Sub-Saharan Africa (SSA) region. ${ }^{11}$

Generally, contraceptive methods were shown to positively affect the hemoglobin level in women differently. ${ }^{14}$ Since the contraceptive method reduces the number of pregnancies and gives space between them, it is recognized as positively impacting lowering Also, modifying the status of hemoglobin level and reducing the risk of anemia is dependent on the individual choice of a contraceptive method. ${ }^{15}$ For example, the use of oral contraceptives with iron supplements was found effective in preventing iron-deficiency anemia. ${ }^{16}$

The prevalence of overweight and obesity in population has reached epidemic percentages, and currently > 650 million adults are either overweight or obese worldwide. ${ }^{17}$ WHO indicated that $67.9 \%$ of adult Americans were overweight and $36 \%$ adults were obese in 2017. Being underweight is the sign of inadequate consumption of micronutrients, and these individuals are vulnerable to anemia. ${ }^{18}$ Even though several studies have been done on the association between anemia and BMI, but the result was inconsistent. One study reported a positive association between anemia and $\mathrm{BMI}^{19}$ whereas other different studies showed a negative association between anemia and adult women's BMI. ${ }^{20-22}$ Additionally, some other studies revealed that there is no association between anemia and BMI. $^{23,24}$ Anemia is not an uncommon condition among women of childbearing age worldwide. Contraception, which is the planning of giving space between births, is believed to beneficial in reducing the anemia in this group of women. However, although some studies are elucidating the connection between the use of contraceptive methods and anemia, the relationship between BMI and anemia is not clear. Moreover, data are scarce in this regard, mainly in the Africa continent and specifically in Ethiopia. Therefore, this study aimed to investigate the association of modern contraceptive methods and BMI with anemia in nonpregnant Ethiopia women of childbearing age. The outcome of this study could help policymakers and governmental and non-governmental groups understand the scope of the problem and the potential causes of anemia so those intervention strategies can be devised.

\section{Method}

\section{Study Design and Population}

Data were driven from the 2015/16 Ethiopia demographic and health survey (EDHS). The survey was conducted with nationally representative samples from all regions of the country. The collected information includes social, behavioral, and demographic indicators, including health status and reproductive health issues, from women aged 15-49. Data were downloaded from the DHS website and displayed in the statistical package (SPSS version 22 IBM US) format.

After pregnant women, menopausal women, postpartum ammonia, those missing data on anemia, and contraceptive use were excluded, 12,981 women of childbearing age were included in the analysis. Figure 1 shows a detailed flow diagram of the data selection procedure. The primary outcome variable was anemia and the predictor variables were modern contraceptive use and BMI and was restricted to women who were not currently pregnant. 


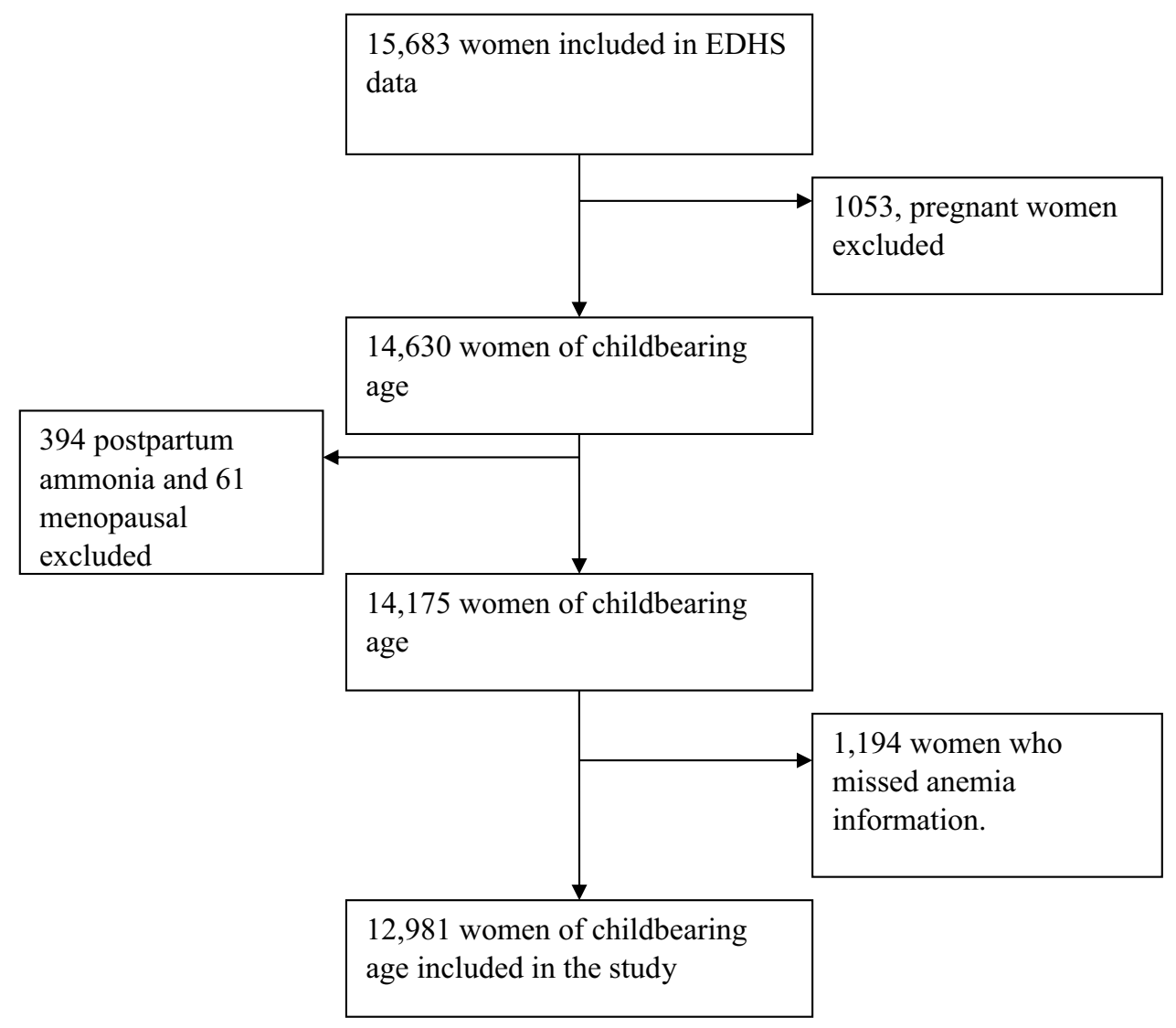

Figure I Flow diagram of exclusion of women of childbearing age to the study.

The EDHS define modern contraceptive use as women childbearing age 15-49 who say they have used at least one of the following modern contraceptive methods: contraceptive pills, implants, male condoms, male and/or female sterilization, injectables, intrauterine contraceptive devices (IUDs), and the lactational amenorrhea method (LAM).

\section{Study Variables}

\section{Dependent and Independent Variables}

The main outcome of this study was anemia. The anemic status of women was defined based on the level of hemoglobin concentration, and was classified as non-anemic (above $12 \mathrm{~g} / \mathrm{dL}$ ) or anemic (below $12 \mathrm{~g} / \mathrm{dL}$ ) and is dichotomous with " 0 " denoting non-anemic or " 1 " is anemia. ${ }^{25}$ The independent variables were a contraceptive method and BMI.

\section{Covariates}

The socio-demographic characteristics such as (women age, educational status, marital status, and the number of children, household members, smoking and household characteristics (residence and wealth status) are used as variates in this study.

\section{Data Analysis}

SPSS version 22 IBM US was used for all statistical analyses, including descriptive and regression models. The data was weighted before analysis to accommodate for the complex sampling design of the surveys. Data weights were estimated based on sampling weights designed to ensure representativeness at country level. Since all variables were categorical, Pearson's Chi-squared test was used to analyze the relationships between the variables. The mean hemoglobin was compared across users of different contraceptive methods using one-way ANOVA. The logistic regression model was used to analyze the association of anemia with modern contraceptive methods and BMI. Confounding variables were identified (women age, educational status, marital status, and the number of children, household members, smoking and household characteristics (residence and wealth status) and adjusted during analysis. The statistical differences were significant with $\mathrm{p}<0.05$.

\section{Ethical Considerations}

The original Demographic health survey (DHS) data were collected following international and national ethical 
guidelines by DHS ethical committee for this study. The researchers registered to use the recode data files of the 2015-16 EDHS with SPSS after receiving approval from the DHS program.

\section{Result}

Out of the 12,981 childbearing women that were included in our analysis, 22.7 (95\% CI: 21.5-23.9) women used at least one of the modern contraceptive methods. Table 1 shows detailed statistics about these women. Following stratification of the data according to maternal age, the lowest was $(23 \%)$ the prevalence of anemia was identified among teenagers (15-19 years), while the highest was $29.5 \%$ among older ( $40-45$ years) women. When considering the type of residence of women who live in rural areas $(19.4 \%)$ are more anemic than in urban areas (29.9\%). Anemia showed the highest (33.5\%) prevalence among those women who were not educated, and it was lowest (14.6) among those women whose level of education was higher than the secondary education. Marital status revealed that married women were highly $(30.0 \%)$ anemic than their counterparts. $31.6 \%$ of underweight women were anemic and followed by $25.3 \%$ of normalweight women. The highest prevalence $(41.1 \%)$ was observed among the lowest wealth quintile, and the lowest prevalence (18.8\%) was among the richest quintile group. Concerning contraceptive method women, those women who used the modern contraceptive methods had less anemia compared to non-users. Moreover, anemia was also found to decrease with an increase in BMI, as the lowest prevalence (20.7) of anemia was found in those women with a BMI of $25 \mathrm{~kg} / \mathrm{m} 2$ and over. In comparison, the highest prevalence (33.5) in women was BMI lower than $18.5 \mathrm{~kg} / \mathrm{m} 2$. Table Supplementary 1 shows in the crosstab the association of contraceptives, BMI, and anemia.

Table 2 demonstrates the fertility and contraceptive use patterns among childbearing age women. Concerning the total number of children ever born or parity, among different women categories, those who had from 5 to 18 children were found to have a higher (34.1\%) rate of anemic compared with those who have no children having the lowest (20.3) and the prevalence of anemia increases with increasing parity. Accordingly, those women who gave birth to 3 and above children in the past five years were more anemic (48.1\%) than those who had not given birth (21.5\%). Furthermore, among those women who gave 1 or more delivery in the recent 1-year, women $(36.9 \%)$ had anemia. Concerning contraceptive
Table I The Association Between Anemia and Basic Characteristics of the Study Population

\begin{tabular}{|c|c|c|c|}
\hline \multirow[t]{2}{*}{ Variables } & \multicolumn{2}{|c|}{ Anemia } & \multirow[b]{2}{*}{ P-value } \\
\hline & No & Yes & \\
\hline \multicolumn{4}{|l|}{ Age } \\
\hline $15-19$ & $2339(24.5)$ & 708 (20.7) & \\
\hline $20-24$ & $1742(18.2)$ & $583(17.1)$ & \\
\hline $25-29$ & $1628(17.0)$ & $638(18.7)$ & \\
\hline $30-34$ & $|27|(13.3)$ & $53 \mid(I 5.5)$ & \\
\hline $35-39$ & $1152(12.0)$ & $448(13.1)$ & \\
\hline $40-44$ & $804(8.4)$ & $310(9.1)$ & \\
\hline $45-49$ & $627(6.6)$ & $200(5.9)$ & 0.000 \\
\hline \multicolumn{4}{|l|}{ Residence } \\
\hline Urban & $3573(37.4)$ & $859(25.1)$ & \\
\hline Rural & $5990(62.6)$ & 2559 (74.9) & 0.000 \\
\hline \multicolumn{4}{|l|}{ Education } \\
\hline No education & $3786(39.6)$ & 1911 (55.9) & \\
\hline Primary edu. & $3420(35.8)$ & $1008(29.5)$ & \\
\hline Secondury edu & $1529(16.0)$ & $358(10.5)$ & \\
\hline Higher edu & $828(8.7)$ & $|4|(4 . \mid)$ & 0.000 \\
\hline \multicolumn{4}{|l|}{ BMI } \\
\hline$<18.5$ & $2199(23.0)$ & $1015(29.8)$ & \\
\hline $18.5-24.9$ & $6151(64.6)$ & 2087 (61.2) & \\
\hline$\geq 25$ & 1178 (12.4) & $307(9.0)$ & 0.000 \\
\hline \multicolumn{4}{|l|}{ Marital status } \\
\hline No & 4274 (44.7) & II5I (33.7) & \\
\hline Yes & $5289(55.3)$ & $2267(66.3)$ & 0.000 \\
\hline \multicolumn{4}{|l|}{ Wealth } \\
\hline Poorest & I85| (19.4) & 1289 (37.7) & \\
\hline Poor & $122 \mid(12.8)$ & $458(13.4)$ & \\
\hline Middle & $1272(13.3)$ & $414(12.1)$ & \\
\hline Richer & I38| (I4.4) & $37 \mid(10.9)$ & \\
\hline Richest & $3838(40.1)$ & $886(25.9)$ & 0.000 \\
\hline \multicolumn{4}{|l|}{ Smoking } \\
\hline No & 9489 (99.2) & 3388 (99.1) & \\
\hline Yes & $74(0.8)$ & $30(0.9)$ & 0.318 \\
\hline
\end{tabular}

Note: $\mathrm{N}$ is given in percentage $(n \%)$.

methods, anemia was found in (30.1\%) non-users women compared to (18.8\%) current users. Besides, in terms of the contraceptive method used, those who use the modern contraceptive method had less prevalence of anemia (18.9\%).

In comparison, a higher prevalence was observed among non-users $(28.7 \%)$. It should be noted that a lesser (14.5) anemia was found in those women using the traditional method. Among those women using contraceptive methods, the highest anemia (55.6\%) was reported in those using female sterilization and followed by those using an intrauterine device (27.6\%), while the least (16.6\%) was among those women using the injection method. 
Table 2 Anemia and Birth Status and Contraceptive Use Pattern Among Women of Reproductive Age in Ethiopia

\begin{tabular}{|c|c|c|c|}
\hline & \multicolumn{2}{|c|}{ Anemia } & \multirow[b]{2}{*}{ P-value } \\
\hline & No & Yes & \\
\hline \multicolumn{4}{|l|}{ Children ever born } \\
\hline 0 & $3680(38.5)$ & $938(27.4)$ & \\
\hline $1-2$ & $2211(23.1)$ & $760(22.2)$ & \\
\hline $3-4$ & $1554(16.3)$ & $623(18.2)$ & \\
\hline $5-18$ & $2118(22.1)$ & $1097(32.1)$ & 0.000 \\
\hline \multicolumn{4}{|c|}{$\begin{array}{l}\text { Number of births in the past } 5 \\
\text { years }\end{array}$} \\
\hline No births & $5669(59.3)$ & $1553(45.4)$ & \\
\hline 1 & $2523(26.4)$ & $953(27.9)$ & \\
\hline 2 & $1164(12.2)$ & $720(21.1)$ & \\
\hline 3 or more & $207(2.2)$ & $192(5.6)$ & 0.000 \\
\hline \multicolumn{4}{|c|}{ Number of births in the past } \\
\hline \multicolumn{4}{|l|}{ I year } \\
\hline No births & $8288(86.7)$ & $2673(78.2)$ & \\
\hline I or more & $1275(13.3)$ & $745(21.8)$ & 0.000 \\
\hline \multicolumn{4}{|c|}{ The pattern of contraceptive use } \\
\hline Never used & $5636(58.9)$ & $2426(71.0)$ & \\
\hline Used before last birth & $655(6.8)$ & $244(7.1)$ & \\
\hline Used since last birth & $727(7.6)$ & $160(4.7)$ & 0.000 \\
\hline Currently using & $2545(26.6)$ & $588(17.2)$ & \\
\hline \multicolumn{4}{|l|}{ Method } \\
\hline No use & $7018(71.3)$ & $2830(28.7)$ & \\
\hline Traditional & $71(85.5)$ & $12(14.5)$ & \\
\hline Modern & $2474(8 I .1)$ & $576(18.9)$ & 0.000 \\
\hline \multicolumn{4}{|c|}{ Modern contraceptive use } \\
\hline Barrier & $35(0.4)$ & $8(0.2)$ & \\
\hline Pills & $180(1.9)$ & $42(1.2)$ & \\
\hline Intrauterine device & $130(1.4)$ & $50(1.5)$ & \\
\hline Injections & $1503(15.7)$ & $299(8.7)$ & \\
\hline Female sterilization & $12(0.1)$ & $15(0.4)$ & \\
\hline Implant & $591(6.2)$ & $155(4.5)$ & \\
\hline Other methods* & $94(1.0)$ & $19(0.6)$ & 0.000 \\
\hline
\end{tabular}

Note: *Includes male sterilization and emergency contraception, $n \%$.

Presented in Table 3 below is the use of contraceptive methods about the status hemoglobin status of the women. The result did not show any significant association between hemoglobin level and contraceptive methods when comparing the group using traditional women who were not using any contraceptive method and the traditional method. However, on the other hand, a one-way analysis of variance shows that the hemoglobin level of modern contraceptive users $(13.1 \pm 1.5 \mathrm{~g} / \mathrm{dl})$ was substantially higher than the corresponding values of non-users $(12.65 \pm 1.8 \mathrm{~g} / \mathrm{dl})$. Moreover, the hemoglobin level of current contraceptive users $(13.1 \pm 1.5 \mathrm{~g} / \mathrm{dl})$ was much higher than non-users $(12.5 \pm 1.8 \mathrm{~g} / \mathrm{dl})$. Regarding different modern contraceptive methods, only female sterilization showed the most negligible hemoglobin value $(11.9 \pm 1.8$ $\mathrm{g} / \mathrm{dl}$ ). There was no significant association between hemoglobin level and other types of modern contraceptive use.

After the confounding was adjusted, the result indicated that modern contraceptive use was $50 \%$ less likely to have anemia than non-users. Similarly, for the pattern of contraceptive uses, adjusted odds ratios were 0.5 (95\% CI; 0.45-0.56), 0.6 (95\% CI; 0.46-0.67), and 0.6 (95\% CI; $0.49-0.96$ ) for the group's women that used before last birth, used since previous birth and currently using, respectively.

The adjusted logistic regression analysis identified that the odds of anemia were substantially reduced by almost $40 \%$ among those who used pills $(\mathrm{AOR}=0.60(95 \% \mathrm{CI}$ : 0.76-1.12)), injections ( $\mathrm{AOR}=0.059$ (95\% CI: 0.24-1.79)), and implants (AOR $=0.72$ (95\% CI: $0.60-0.86))$ users compared to barrier method users. Conversely, no significant reduction in anemia was observed among users of IUD, female sterilization, and other modern methods.

Furthermore, the results in Table 3 showed a positive association between BMI and anemia. The odds ratio of underweight before adjustments of confounders were (OR 1.12 (95\% CI 1.01-1. 78)) $\mathrm{P}=0.002$; and after the confounders were adjusted, the underweight women showed a significant effect on anemia (OR 2.20 (95\% CI 1.58-2. 62)) $\mathrm{P}=0.000$. And the result illustrated that there was no association between overweight women and anemia.

\section{Discussion}

In the present study, we demonstrated a robust positive association between modern contraceptive methods and anemia and hemoglobin levels. This study showed that some modern contraceptive methods such as; pills, injections, and implants showed less anemia among women of childbearing age in Ethiopia. Besides, our result depicts a common effect of BMI on hemoglobin level.

In this study, the result identified among current users of pills, the odds ratio of 0.6 (95\% CI: 0.45 to 1.12$)$, of anemia which indicates the risk of anemia was reduced by $40 \%$ compared with users of the barrier method. Similarly, other studies based on DHS data of sub-Sahara countries elucidate that the use of oral contraceptive pills (OCP) reduces the odds of anemia by $38 \%{ }^{26}$ Moreover, Saverio and his colleagues reported in a study of low and middleincome countries, the duration of OCP use increases, the odds of anemia among OCP were reduced from $32 \%$ to $44 \%$ for at least 6 months and 2 or more years, 
Table 3 Contraceptive Use, BMI, and Hemoglobin Status Among Women of Childbearing Age

\begin{tabular}{|c|c|c|c|c|c|c|c|}
\hline \multirow[b]{2}{*}{ Total population } & \multirow{2}{*}{$\begin{array}{c}\text { Mean (士SD) Hemoglobin }(\mathrm{g} / \mathrm{dl}) \\
12.8 \pm 1.7\end{array}$} & \multicolumn{3}{|c|}{ COR } & \multicolumn{3}{|c|}{ AOR } \\
\hline & & & & & & & \\
\hline Method & & OR & $95 \% \mathrm{Cl}$ & P-value & OR & $95 \% \mathrm{Cl}$ & P-value \\
\hline No use & $12.65 \pm 1.8$ & 1 & & & 1.00 & & \\
\hline Traditional & $13.2 \pm 1.3$ & 0.5 & $0.22-0.77$ & 0.005 & 0.6 & $0.29-1.02$ & 0.058 \\
\hline Modern & $13.1 \pm 1.5$ & 0.54 & $0.52-0.63$ & 0.000 & 0.5 & $0.49-0.61$ & 0.000 \\
\hline \multicolumn{8}{|c|}{ Pattern of contraceptive use } \\
\hline Never used & $12.5 \pm 1.8$ & 1 & & & 1 & & \\
\hline Used before last birth & $12.7 \pm 1.6$ & 0.5 & $0.48-0.59$ & 0.000 & 0.5 & $0.45-0.56$ & 0.000 \\
\hline Used since last birth & $13.1 \pm 1.5$ & 0.5 & $0.42-0.611$ & 0.000 & 0.6 & $0.46-0.67$ & 0.000 \\
\hline Currently using & $13.1 \pm 1.5$ & 0.86 & $0.74-1.01$ & 0.067 & 0.62 & $0.49-0.96$ & 0.017 \\
\hline \multicolumn{8}{|c|}{ Modern contraceptive use } \\
\hline Barrier & $13.2 \pm 1.5$ & 1 & & & I & & \\
\hline Pills & $13.1 \pm 1.4$ & 0.6 & $0.4 I-0.8 I$ & 0.002 & 0.6 & $0.45-1.12$ & 0.013 \\
\hline Intrauterine device & $12.9 \pm 1.6$ & 1.05 & $0.68-1.32$ & 0.778 & 1.05 & $0.89-1.24$ & 0.704 \\
\hline Injections & $13.2 \pm 1.5$ & 0.5 & $0.43-0.56$ & 0.000 & 0.59 & $0.24-1.79$ & 0.000 \\
\hline Female sterilization & $11.9 \pm 1.8$ & 3.1 & $1.45-6.63$ & 0.004 & 1.43 & $1.17-1.75$ & 0.062 \\
\hline Implant & $13.1 \pm 1.6$ & 0.6 & $0.54-0.78$ & 0.000 & 0.72 & $0.60-0.86$ & 0.009 \\
\hline Other method & $13.1 \pm 1.6$ & 0.5 & $0.31-0.82$ & 0.006 & 1.65 & $1.38-1.99$ & 0.070 \\
\hline \multicolumn{8}{|l|}{ BMI } \\
\hline $18.5-24.9$ & $12.8 \pm 1.7$ & 1 & & & & & \\
\hline$<18.5$ & $11.1 \pm 1.2$ & 1.12 & $1.01-1.78$ & 0.002 & 2.20 & $1.58-2.62$ & 0.000 \\
\hline$\geq 25$ & $13.6 \pm 1.9$ & 0.87 & $1.01-1.78$ & 0.456 & 0.95 & $0.8-1.16$ & 0.954 \\
\hline
\end{tabular}

Note: Adjusted for household wealth index, age, total children ever born, educational status, marital status, place of residence (urban/rural), household size. Abbreviations: COR, crude odds ratio; AOR, adjusted odds ratio.

respectively. ${ }^{16}$ Another study reported that the use of OCP showed an improvement in hemoglobin levels among anemic women, especially after long-term use. ${ }^{27}$

In line with the study by Samson and his colleague, ${ }^{26}$ our research revealed that the odds of anemia were 0.59 (95\% CI: 0.24 to 1.79 ) and reduced by $41 \%$ for injections users compared with other barriers type users. Similarly, the same study demonstrated that those women who use injectables for a prolonged time, like a year or more, were associated with a reduction of anemia. ${ }^{26}$ We observed a $38 \%$ reduction in the odds of anemia among implant users than counterparts; parallel to this study, the use of implants was also found to minimize the level of anemia by $37 \%$ among childbearing age women. ${ }^{26}$ Most of the implant users do not have a consistent menstrual cycle and frequently change, with lighter and fewer bleeding days; thus, infrequent or missing the period might be the reason for the reduction of anemia. ${ }^{26}$

Regarding IUD, the results of our study revealed that there was no significant difference in the amount of hemoglobin level and no association between IUD and anemia. Inconsistent with this study, the use of the copper intrauterine device (cu-IUD) was shown to cause massive bleeding and concomitantly enhanced the risk of anemia. ${ }^{28}$
Our study also evaluated the effect of BMI on anemia, and the result showed a positive association with anemia. Notably, underweight non-pregnant women showed a significant impact on anemia, compared to normal-weight women; underweight non-pregnant women were 2.20 times more likely to have anemia. Consistent with our findings, a study also confirmed that underweight non-pregnant women of childbearing age were 4.07 times more probably to have anemia than those with BMI $\geq 18.5 \mathrm{~kg} / \mathrm{m}^{2} .{ }^{29}$ Similarly, other results showed that compared to overweight/obese women, those normal weight/ underweight women were more likely to suffer from anemia. ${ }^{18}$

The study's strength is that large-scale and nationally representative data from different regions of the countries where anemia is a public health problem. DHS questionnaires are standardized and pretested to ensure comparability over time and across populations. However, this study had some limitations and possible biases to this study. As the survey was conducted in 2016, the prevalence of anemia and BMI status might have changed since then. The findings can also be affected by selection bias as there is no guarantee that the characteristics of the contraceptives' users had been the same at baseline. Besides, the DHS dataset does not present all necessary information about the contraceptives used by the individuals. 
In conclusion, the present study identified that using modern contraceptive methods, especially hormonal contraceptive use such as Pills, implants, and injections, reduces the risk of anemia in women of childbearing age from Ethiopia. Besides, our result highlighted the positive association between BMI and better hemoglobin levels.

\section{Acknowledgment}

The authors would like to thank DHS for granting free access to the data.

\section{Disclosure}

The authors report no conflicts of interest in this work.

\section{References}

1. Tripathi AD, Mishra R, Maurya KK, et al. Estimates for world population and global food availability for global health. In: The Role of Functional Food Security in Global Health. Elsevier; 2019:3-24.

2. Zheng B, de Beurs KM, Owsley BC, Henebry GM. Scaling relationship between $\mathrm{CO}$ pollution and population size over major US metropolitan statistical areas. Landsc Urban Plan. 2019;187:191-198. doi:10.1093/rpd/ncz154

3. Sserwanja Q, Musaba MW, Mukunya D. Prevalence and factors associated with modern contraceptives utilization among female adolescents in Uganda. BMC Womens Health. 2021;21(1):61. doi:10.1186/s12905-021-01206-7

4. Obasohan PE. Religion, ethnicity and contraceptive use among reproductive age women in Nigeria. Int $J$ MCH AIDS. 2015;3(1):63.

5. Tobe A, Nahusenay H, Misker D. Factors associated with modern contraceptive service utilization among married reproductive age women in Melo Koza Woreda, southern Ethiopia. J Pregnancy Child Health. 2015;2:128.

6. Jones RK, Dreweke J. Countering Conventional Wisdom: New Evidence on Religion and Contraceptive Use. New York, NY: Alan Guttmacher Institute; 2011.

7. Kayode GA, Adekanmbi VT, Uthman OA. Risk factors and a predictive model for under-five mortality in Nigeria: evidence from Nigeria demographic and health survey. BMC Pregnancy Childbirth. 2012;12(1):10.

8. Hatcher R., et al., Contraceptive Technology, revised 20th ed; 2011. New York, N.Y.: Ardent Media, (C2007

9. Wang C, Cao H. Persisting regional disparities in modern contraceptive use and unmet need for contraception among Nigerian Women. Biomed Res Int. 2019;2019. doi:10.1155/2019/9103928

10. O'Regan A, Thompson GJC. Indicators of young women's modern contraceptive use in Burkina Faso and Mali from demographic and health survey data. Contracept Reprod Med. 2017;2(1):26. doi:10.1186/s40834-017-0053-6

11. World Health Organization. The global prevalence of anemia in 2016. Geneva: WHO; 2016. Accessed May 9, 2016.

12. Ko MK, Win HH, MacQuarrie KL. Regional disparities and determinants of anemia and modern contraceptive use among women in Myanmar further analysis of the Myanmar demographic and health survey 2015-16. USAID; June, 2019.
13. World Health Organization, Geneva, Switzerland. Haemoglobin Concentrations for the Diagnosis of Anaemia and Assessment of Severity. Vitamin and Mineral Nutrition Information System. Document Reference WHO. NMH/NHD/MNM/11.1; 2011. Available from: http://www.who.int/entity/vmnis/indicators/ haemoglobin.

14. World Health Organization. The global prevalence of anaemia in 2011 [Internet]. Geneva, Switzerland: World Health Organization; 2015.

15. World Health Organization. Effects of contraceptives on hemoglobin and ferritin. Task Force for Epidemiological Research on Reproductive Health, United Nations Development Programme/ United Nations Population Fund/World Health Organization/World Bank Special Programme of Research, Development and Research Training in Human Reproduction, World Health Organization, Geneva, Switzerland. Contraception. 1998;58(5):262-273.

16. Bellizzi S, Ali MM. Effect of oral contraception on anemia in 12 low-and middle-income countries. Contraception. 2018;97 (3):236-242. doi:10.1016/j.contraception.2017.11.001

17. World Health Organization. Obesity and Overweight; 2017.

18. Ghose B, Yaya S, Tang S. Anemia status in relation to body mass index among women of childbearing age in Bangladesh. Asia Pac $J$ Public Health. 2016;28(7):611-619. doi:10.1177/10105395 16660374

19. Cepeda-Lopez AC, Osendarp SJ, Melse-Boonstra A, et al. Sharply higher rates of iron deficiency in obese Mexican women and children are predicted by obesity-related inflammation rather than by differences in dietary iron intake. Am J Clin Nutr. 2011;93(5):975-983.

20. Qin Y, Melse-Boonstra A, Pan X, et al. Anemia in relation to body mass index and waist circumference among Chinese women. Nutr J. 2013;12(1):1-3.

21. Palupi KC. Interactive effects of dietary fat/carbohydrate ratio and body mass index on iron deficiency anemia among Taiwanese Women; 2014.

22. Neymotin F, Sen U. Iron and obesity in females in the United States. Obesity. 2011;19(1):191-199. doi:10.1038/oby.2010.112

23. Ausk KJ, Ioannou GN. Is obesity associated with anemia of chronic disease? A population-based study. Obesity. 2008;16(10):2356-2361. doi:10.1038/oby.2008.353

24. Fanou-Fogny N, J Saronga N, Koreissi Y, et al. Weight status and iron deficiency among urban Malian women of reproductive age. $\mathrm{Br}$ J Nutr. 2011;105(4):574-579. doi:10.1017/S0007114510003776

25. Liyew AM, Teshale AB. Individual and community level factors associated with anemia among lactating mothers in Ethiopia using data from Ethiopian demographic and health survey, 2016; a multilevel analysis. BMC Public Health. 2020;20:1-11. doi:10.1186/s12889-020-08934-9

26. Gebremedhin S, Asefa A. Association between type of contraceptive use and haemoglobin status among women of reproductive age in 24 sub-Saharan Africa countries. BMJ Sex Reprod Health. 2019;45 (1):54-60. doi:10.1136/bmjsrh-2018-200178

27. Bathija H, Lei ZW, Cheng XQ, et al. Effects of contraceptives on hemoglobin and ferritin. Contraception. 1998;58(5):261-273.

28. Curtis KM, Tepper NK, Jatlaoui TC, et al. US medical eligibility criteria for contraceptive use, 2016. MMWR Morb Mortal Wkly Rep. 2016;65(3):1-103. doi:10.15585/mmwr.mm6501a1

29. Asres Y, Yemane T, Gedefaw L. Determinant factors of anemia among nonpregnant women of childbearing age in southwest Ethiopia: a community based study. Int Sch Res Notices. 2014;2014:1-8. doi:10.1155/2014/391580 


\section{Publish your work in this journal}

Open Access Journal of Contraception is an international, peerreviewed, open access, online journal, publishing original research, reports, reviews and commentaries on all areas of contraception. In addition to clinical research, demographics and health-related aspects, the journal welcomes new findings in animal and preclinical studies relating to understanding the biological mechanisms and practical development of new contraceptive agents. The manuscript management system is completely online and includes a very quick and fair peer-review system. Visit http://www.dovepress.com/testimonials. php to read real quotes from published authors. 